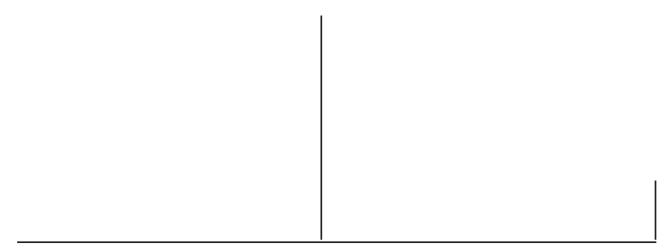

Rev. Latinoam. Psicopat. Fund., V, 4, 11-29

\title{
O ensino da psicopatologia: do modelo asilar à clínica da interação*
}

\author{
Ademir Pacelli Ferreira
}

A questão do ensino da psicopatologia é aqui abordada a partir da retomada de elementos da história da constituição da clínica médica e dos clássicos, até a constituição da psiquiatria clínica. Neste percurso, analisa-se os instrumentos nascidos da atenção cuidadosa para com o padecimento e, posteriormente, com a conquista do domínio sobre a doença por meio da nosografia, onde a marca pessimista do asilo tornou a clínica um exercício escolástico. Propõe-se, então, um retorno à clínica contra o empiricismo e o essencialismo clinicista.

Palavras-chave: Clínica clássica, psicopatologia, ensino, psicopatologia fundamental

* Este texto surgiu de uma primeira versão apresentada no VI Encontro Científico da Rede Universitária de Pesquisa em Psicopatologia Fundamental - Petrópolis - set/2001. Agradeço a Margarete Ferreira pela leitura e contribuições ao texto, e a Maria Lúcia Gonçalves pela revisão do português. 


\section{Introdução}

Várias são as questões que envolvem o ensino da psicopatologia e da psiquiatria. Pretendo, com este artigo, continuar o debate iniciado no VI Encontro Científico da Rede de Psicopatologia Fundamental, visando manter a interlocução e o interesse nesta área. Apesar do título poder sugerir a idéia de uma epopéia histórica, não se trata, na verdade, de uma análise histórica, mas sim da utilização de alguns elementos da história que permitiram o surgimento da experiência clínica para, então, revalorizá-la. A clínica constituída no final do século XVIII ofereceu aos médicos alienistas um método de observação e de organização da loucura num sistema racional. O clinicismo atravessou longos períodos, desde o olhar puro (Foucault, 1977) que, junto ao leito transformado em santuário da investigação, aliouse ao dizer e organizou a sua experiência, delimitando a polissemia do sofrimento no interior do corpo do indivíduo. Hoje, o estudo da psicopatologia tende a tornar-se secundário na formação do psiquiatra, já que o diagnóstico seria derivado da captação da presença estatística de determinados sinais. Portanto, esta argumentação espera poder sustentar o retorno à clínica, onde a psicopatologia geral e a psicopatologia fundamental são convidadas a interagirem.

A partir de uma longa experiência de ensino e assistência em uma unidade universitária de psiquiatria, ${ }^{1}$ encontrei, na proposição do VI Encontro Científico da Rede, a oportunidade de iniciar o debate sobre esta temática. Sua relevância se coloca logo de início pela carência de bibliografia sobre o assunto, além disso, parece haver um

1. Unidade Docente Assistencial de Psiquiatria do HUPE da Universidade do Estado do Rio de Janeiro (UDAP). 


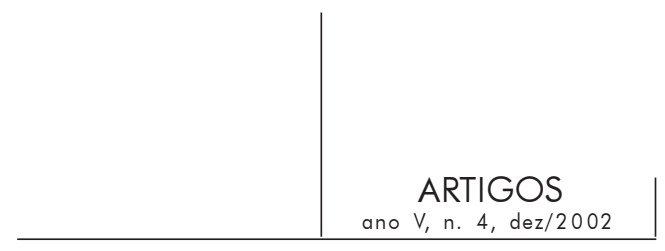

certo desencanto em relação ao estudo psicopatológico. A psiquiatria nasceu da entrada dos médicos no asilo e do encontro com a psicologia clássica, que forneceu os subsídios para a organização da psicopatologia. Mas procurou se manter respaldada na autoridade moral e jurídico da medicina. Se a bipolaridade (Kammerer, 1989) médico-psicológica se manteve por longos anos, com a hegemonia da referência biotecnicista (Canguilhem, apud Americano do Brasil, 2001) das últimas décadas, a formação psiquiátrica vem perdendo o interesse pelo psíquico e pelo páthos (Caon, 2002).

Na formação do psicólogo, a disciplina de psicopatologia consta desde o início da criação das faculdades de psicologia que, a partir da década de 1970, expandiram-se em todo o país. Junto com o ideal clínico, a psicologia importou também o modelo médico como ideal de formação do psicólogo. A disciplina de psicopatologia tem sido lecionada quase exclusivamente por psiquiatras, até mesmo porque, antes, não dispúnhamos de psicólogos capacitados para tal. Suponho ter sido um dos primeiros psicólogos encarregados pela disciplina. Desde o início de minha experiência, procurei aliar o ensino com a extensão junto à clínica psiquiátrica. Trata-se de uma rica experiência interdisciplinar, já que, além do curso de graduação, da supervisão de estagiários e de residentes de psicologia, participo do atendimento ao paciente internado, do Hospital-Dia e do ambulatório. Neste sentido, discutimos todos procedimentos clínicos: diagnóstico, programa terapêutico, recursos técnicos e institucionais, internação e alta, prognóstico e continuidade do tratamento externo.

No curso de psicologia, a psicopatologia foi dividida em Geral e Especial. A primeira, nos moldes de Jaspers - um tipo de psicologia geral do patológico estuda os distúrbios das funções psíquicas, da personalidade e do comportamento. A psicopatologia especial, equivalente da psiquiatria clínica, engloba os métodos de classificação, propedêutica e nosologia psiquiátrica. Sabe-se que a nomenclatura psicopatológica nasceu de uma experiência prática contínua nos manicômios, sendo, portanto, essencialmente empírica. Seu ensino, tradicionalmente, também foi desenvolvido pelo contato diário com casos clínicos, observações, exames e intervenções práticas. No entanto, os estudantes de psicologia não dispõem desta experiência clínica, o que torna mais difícil a aprendizagem da diferenciação dos termos e conceitos psicopatológicos.

Hospital e hospício: um campo natural de ensino

No final do século XVIII, o hospital foi transformado em locus privilegiado para o ensino médico. Esperava-se que daí surgissem as grandes lições - 


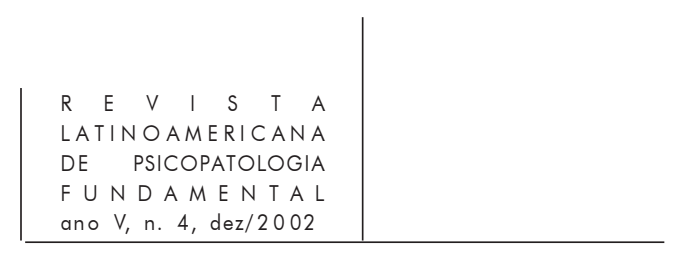

através das doenças e da morte - ao permitir "descrever a história dos males, e ensinar a arte de observar e tratar as doenças" (Foucault, 1977, p. 71). Foi a partir da observação aguçada, e em profundidade, que se criou tanto a experiência clínica quanto o discurso de estrutura científica sobre o indivíduo. A experiência clínica "abriu" o "indivíduo concreto à linguagem da racionalidade, acontecimento capital da relação do homem consigo mesmo e da linguagem com as coisas" (Ibid., p. XIII). Se a doença do corpo foi domesticada no leito pela racionalidade médica, no final do século XVIII, a loucura, por seu turno, encontrava-se dispersa na urbis e no asilo. Os chamados asilos ou hospícios serviam como espaços depositários daquilo que perturbava a pólis. Os médicos alienistas, ao penetrarem nestes espaços, deveriam aí introduzir uma experiência de domínio sobre a coisa da loucura que atiçava os sentidos, fornecendo-lhe uma estrutura a partir da racionalidade médica. Estava fundado, então, o campo ideal para a observação e catalogação das manifestações da loucura, ordenadas, aos poucos, em famílias, gêneros e espécies, fundando uma prática que resultou na criação da psiquiatria como disciplina médica.

Depois do advento dos psicotrópicos, os psiquiatras vislumbraram a possibilidade de exercer suas práticas em consultórios, como já o faziam as outras categorias médicas. Entretanto, se os neurolépticos favoreceram uma internação mais curta, não conseguiram evitar o aumento das reinternações, já observadas na década de 1950 e tornadas críticas na década de 1970 (Silveira, 1982), o que favoreceu a expansão dos hospícios e a sua continuidade como lugar-depositário da loucura na representação social. Desta forma, o espírito da segregação aciona, automaticamente, a defesa da internação frente a qualquer expressão de loucura. Talvez se defenda tenazmente a continuidade do hospício, devido a este lugar social que ocupou e que indicamos anteriormente. Esta hipótese pode justificar a intensa reação emocional de seguimentos da sociedade e de profissionais e professores da área psiquiátrica, contra o projeto de reforma da assistência psiquiátrica que visa acabar com a segregação e limitar o período de internação. Além da defesa de interesses econômicos de corporações, é como se estivesse em jogo a própria identidade profissional. Para alguns professores, o possível fim dos manicômios era entendido como o fim do ensino da psiquiatria.

Se a invisibilidade da loucura dificultava a clínica do olhar, o asilo tornouse o locus da visibilidade exibindo as várias espécies nosográficas. Foi neste campo de visibilidade que os alienistas que, a partir de Pinel, diferenciaram os alienados do resto dos asilados e construíram um corpo de descrições que derivaram na nosografia que herdamos. Todo este esforço tinha a finalidade de garantir uma nova especialidade médica - a psiquiatria. Mas esta clínica das descrições minuciosas trazia também, em seu bojo, a marca pessimista do asilo. Esta prática psiquiátrica tão cara aos alienistas ávidos por captar, identificar, descrever e di- 


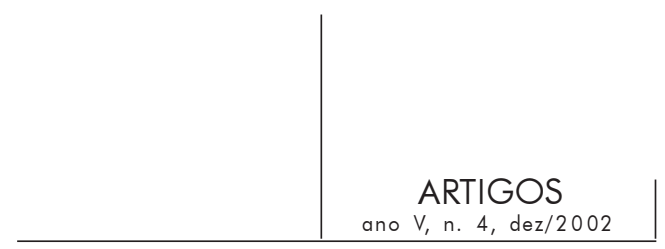

ferenciar entidades mórbidas, ficou caracterizada como simples exercício acadêmico, pois nela, o diagnóstico negava a própria práxis terapêutica. Jung (Correspondência Freud/Jung, 1986, p. 15), em suas Memórias, descreve o famoso Burgolzli dirigido por Bleuler, e onde foi chefe de clínica por vários anos, como a cultura do provável, do mediano, do convencional e destituído de sentido, onde se renunciava ao estranho e ao significativo, e o extraordinário era reduzido ao banal. Por conseguinte, "havia apenas (...) estreitos horizontes opressivos e o deserto infindo da rotina".

\section{O mal-estar no ensino psiquiátrico: sem ver, sem auscultar, sem apalpar}

Este tripé acima citado, tornou-se instrumento sensível de aproximação e exame da clínica médica, apesar de que hoje, muitas vezes o médico prefira pedir um ecocardiograma antes mesmo da ausculta do coração (Chenieaux Jr., 2002). Para a psiquiatria, desde o início, estes instrumentos não eram de grande utilidade: como ver, como apalpar e como auscultar os sintomas psicopatológicos? Na minha experiência em um hospital geral, onde atuei junto a uma equipe de clínica médica, surpreendia-me a ênfase dada à prática de ver casos. A metodologia de discussão dos casos em atendimento com os residentes de medicina foi desqualificada em detrimento da ênfase em ver o maior número possível de casos.

O modelo de formação dos alienistas no século XIX seguia a mesma tradição da clínica médica constituída no final do século XVIII. Nesta, o candidato deveria estar ao lado do grande mestre e seguir os seus passos no dia a dia, observando e examinando os doentes para aprender a detectar os mínimos sinais, a catalogá-los e conceituá-los. Nesta clínica do olhar (Foucault, 1977), o aspirante deveria desenvolver a perícia da observação, a partir do treinamento diário junto ao mestre. Já no final do século XIX, esta clínica do olhar ganhou instrumentos competentes de produção e demonstração em cena das alterações psíquicas. Charcot, por exemplo, se consagrou como o mestre das histéricas, por meio das demonstrações sensacionais dos mecanismos sugestivos de produção dos seus sintomas. ${ }^{2}$ Mais tarde, Clérambault [1920](1999), dando continuidade à prática de ensino da escola alemã, tornou-se perito na apresentação de

2. Freud, citado por Quinet (2001, p. 84) assim caracteriza Charcot: “... ele não negligenciava nada do que pudesse penetrar em seu espírito pelos olhos, ele não falava jamais de um paciente sem apresentá-lo a seu auditório, ele não descrevia jamais um sintoma sem fazê-lo ao mesmo tempo constatar de visu”. 


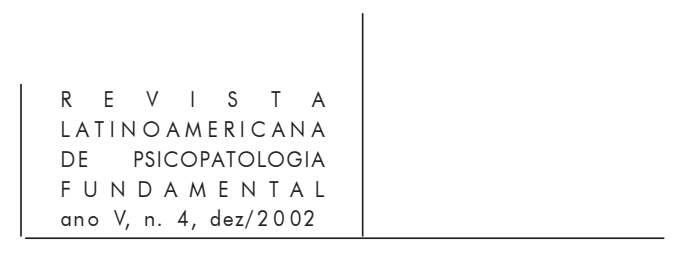

pacientes. Foi aí que Lacan o encontrou e o nomeou seu mestre. Mesmo depois de tornar-se psicanalista, Lacan continuou a praticar este método no ensino da psiquiatria, inspirando alguns seguidores que, hoje, estão retornando aos hospícios para desenvolverem a prática da apresentação de pacientes.

Mas este ensino que ganhou legitimidade e eficácia do ponto de vista operatório (Pereira, 1998), e que levou a psiquiatria a ser considerada como primeira especialidade médica (Foucault, apud Americano do Brasil, 2001), teve, por outro lado, dificuldades de provar a consistência de seu objeto frente à medicina que a respalda. A partir da impotência de detectar a loucura por meio dos sinais sensoriais, os médicos procuraram traçar uma outra geografia. Foi necessário inventar uma cartografia da alma e de suas faculdades para fundar a disciplina da psicopatologia. Esta vem suprir a carência de uma anátomo-fisiologia para os novos peritos. Mas se os conceitos operatórios foram eficazes na condução da propedêutica psiquiátrica, faltou-lhes, por outro lado, uma consistência epistemológica, por isso o ensino se caracteriza mais como um treinamento. Como afirma Americano do Brasil (2001, p. 82), “... a pedagogia e a experiência são os meios que operacionalizam a ação da formação psiquiátrica, mas não se transmite a sustentação epistêmica deste campo".

Ao me contrapor à redução da prática clínica à captação dos sintomas através do visível ou do sensorial, não estou refutando a análise semiológica e a importância dos instrumentos propedêuticos, mas afirmando que essa redução empobrece a visão sobre o sofrimento humano. Por isso, enfatizo a importância da vivência e da experiência com o doente na formação do clínico e do psicopatólogo (cf. Caon, 2002). Na ótica positivista, voltada para a percepção da presença-ausência de sinais previstos nos código classificatórios, torna-se difícil a discussão dos elementos subjetivos. Se a psicanálise e a fenomenologia puderam manter uma longa interlocução, a partir do domínio do modelo estatístico do DSM-IV, ${ }^{3}$ torna-se impossível esta contribuição, pois tudo que é subjetivo é visto como perturbador ao modelo da quantificação. Até mesmo diferenciar idéia delirante de idéia deliróide; uma alucinação verdadeira de uma pseudo-alucinação, torna-se supérfluo, já que os antipsicóticos irão atuar sobre esses sintomas do mesmo jeito (cf. Cheniaux Jr., 2002)

Se a clínica médica nasceu da escuta atenciosa das queixas do doente, com o estabelecimento da nosografia e de um olhar clínico diferenciador, o médico

3. Surgido em 1952 nos Estados Unidos, o Manual Diagnóstico e Estatístico dos Transtornos Mentais (DSM-I) visa, desde o início, à universalidade, ampliando seu domínio dos limites da Associação Psiquiátrica Americana para o mundo. Do processo de elaboração e sistematização continuado resultou as novas versões: DSM-II (1968); DSM-III (1979); DSM-III-R (1986) e DSM-IV (1994) (Ionescu, 1997). 


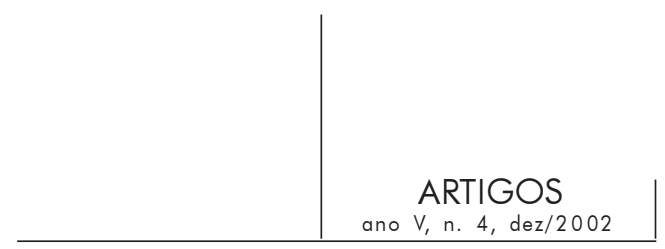

passou a ter um domínio sobre as doenças e afastou-se mais do doente. Com o olhar perscrutador, visa, então, captar os sinais que irão compor uma determinada doença. Sua perícia passa a ser medida por esta capacidade de objetividade. Este domínio transformou o médico em mestre das doenças. Nesta perspectiva, a fala do paciente só tem sentido se é possível decodificá-la em uma semiologia médica. O que é subjetivo, como as queixas dos neuróticos, que não possuem esta objetividade, sempre criaram um mal-estar, como as histéricas do final do século XIX, que desafiaram o médico neste lugar de mestre. Com suas solicitações e com seus sintomas funcionais, pareciam provocar e tapear o médico.

\section{O paciente em cena: o lugar da ilustração}

Neste domínio de um saber sobre as doenças, introduziu-se o ensino prático através da apresentação de pacientes. Este artifício de transmissão da psicopatologia ainda desperta controvérsias. Diferencio aqui a prática de entrevistas clínicas realizadas pelo professor, juntamente com os residentes ou especializandos responsáveis pelo atendimento dos pacientes entrevistados, daquelas aulas para turmas de alunos de graduação. Nestas, os alunos não possuem nenhum vínculo com o paciente. Trata-se de um exercício meramente didático, onde não há lugar para a produção de uma fala significativa do sujeito, à medida que este é reduzido à condição de objeto de estudo. Em sua práxis de longos anos, Nise da Silveira instituiu uma outra perspectiva ética de ensino e de relação com o doente mental, onde o respeito pelas vivências e produções subjetivas não permitia tratar o paciente como objeto. Na minha experiência de mais de duas décadas de atividades docentes-assistenciais na instituição psiquiátrica, não considero que haja ganho nestas apresentações de pacientes, seja para o tratamento, seja para o ensino-aprendizagem. Tenho encontrado vários professores e psiquiatras que, também, são críticos deste recurso. Em conversas com alunos de medicina, uma grande parte ainda afirma não ter se beneficiado por este recurso didático. Muitos afirmam, ainda, que esta experiência aumenta o preconceito à chamada doença mental. Entendo que esta prática favorece a alienação de todos os envolvidos, o doente, o aluno e o professor, à medida que aborda um objeto de estudo sem nenhum compromisso ético (terapêutico) com o sujeito em sofrimento.

Apesar das justificativas éticas (morais) que sustentam este recurso, à medida que visaria o ensino, o esclarecimento do caso e o progresso da ciência e da técnica, no que se refere ao ensino da psicopatologia, estas justificativas não nos convencem. Observo, com freqüência, o surgimento de reações de descon- 


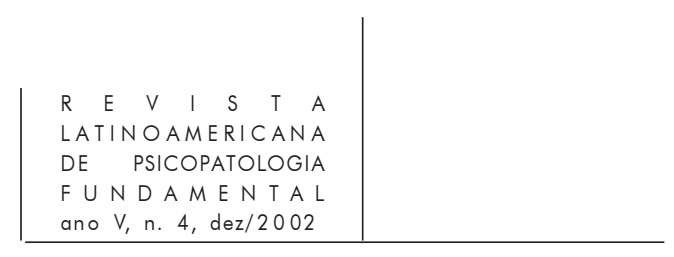

fiança e de oposição, após a exposição de pacientes nestas aulas. Queixam-se de se sentirem como ratos de laboratório, de estarem ali só para estudo e de não se sentirem ajudados em seus sofrimentos pelos profissionais.

Logo que me ingressei como professor, fui encarregado de organizar um programa prático para esta disciplina de psicopatologia. Sugeri, então, que os alunos visitassem a enfermaria, procurando, ali, manter contato e algum nível de convivência com as pessoas internadas. Estimulamos ainda que mantenham uma conversa informal e a participação em atividades criativas e grupais. Em nossa avaliação, é possível estabelecer algum contato significativo neste tipo de experiência, o que pode resultar no desenvolvimento de concepções e de representações menos estereotipadas sobre o doente mental. Neste tipo de proposta, o que primeiro chamou a nossa atenção foi o confronto entre as imagens coletivas da loucura, que povoavam o imaginário dos alunos, com a experiência da convivência. Posso afirmar que, para esses alunos, a surpresa maior foi a descoberta de que, em vez de loucos, encontravam-se ali pessoas com vida subjetiva e objetiva, com desejos, valores, conflitos, qualidades e defeitos.

Hoje, lembrando do único contato que tive com este recurso, vejo que foi bastante estranho. No início dos inícios (1973), no Centro Psiquiátrico Pedro II, atual Instituto Nise da Silveira, entrei num auditório para assistir uma palestra e me deparei com uma aula com apresentação de paciente. Com uma platéia em torno de cinqüenta pessoas, depois das preliminares - suponho que considerações sobre a paranóia ou esquizofrenia paranóide - chegou o momento da cena anunciada, adentra no recinto uma enfermeira conduzindo um homem até o palco; altivo, esguio, gestos anunciadores e concentrado em seu papel. Ele assumiu, então, a palavra, convocando os estudantes a escutarem a sua paródia delirante sobre seu projeto de reforma do mundo. Falou durante uns vinte minutos, num discurso encadeado e pronto para a platéia, até que o mestre de cerimônia (o psiquiatra) interrompeu a sua preleção, agradecendo-lhe e orientando a enfermeira para levá-lo de volta à enfermaria.

Satisfeito com a sua façanha, o ocupante do discurso do mestre fez suas considerações, indicando os sinais que comprovavam o sistema delirante do paciente. Saí dali com a impressão de que o objetivo visado pelo professor era o de demonstrar que as idéias socialistas e os ideais revolucionários eram frutos de delírio. ${ }^{4} \mathrm{O}$ papel da platéia estava bem delineado, tratava-se do lugar do olhar, função de contemplar a cena ou a encenação do ensino prático.

4. As reclamações, denúncias e análises críticas, durante o milagre brasileiro da década de 1970, eram vistas como atitudes querelantes dos pessimistas. Juntamo-nos ao escritor português Saramago, ao defender a importância dos pessimistas, que não se deixam cair no engodo do otimismo e se mantêm críticos frente ao entusiasmo ilusório dos que estão levando vantagens neste sistema tão desvantajoso para a maioria. 


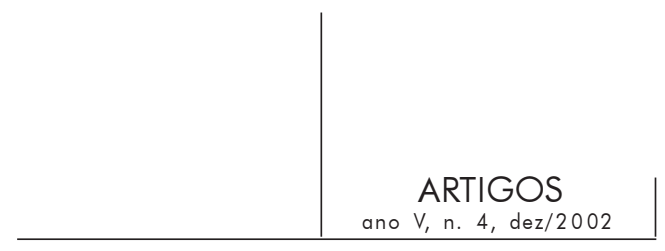

Também Vertzman (1996) parte da crítica à apresentação de pacientes para refletir sobre a transformação do ensino. Ilustra sua crítica com duas cenas onde se viu como espectador numa e como professor, noutra. $\mathrm{Na}$ primeira cena como aluno, descreve as fantasias dos alunos frente à expectativa da entrada do novo paciente, onde, diante do acontecimento fetiche do ensino prático, o que predominava nas representações da platéia, segundo ele, era a curiosidade dos alunos sobre a próxima bizarrice a que iriam assistir.

Na segunda cena, Vertztman relata sua experiência como professor. Nesta, com um pequeno grupo de estudantes de psicologia, ele reproduz o ensino prático, apresentando uma mulher que se encontrava internada. A paciente quase não fala. Com esforço, queixava-se de que já não tem lágrimas para chorar e que sua vida acabara há muitos anos. O professor, no caso o próprio, insistia para que os sintomas que compõem o quadro de depressão aparecessem e se presentificassem no aqui e agora, visando à ilustração de sua aula prática. Para as várias perguntas de praxe, a paciente responde de forma arrastada. Ao término da sessão-aula, uma aluna se arrisca a falar sobre seu mal-estar frente a esta prática, onde não há possibilidade de estabelecimento de uma comunicação autêntica com o paciente, já que este teria que falar de sua intimidade para pessoas desconhecidas, com as quais não tinha nenhuma relação. Agora, ironizando, este autor expõe os argumentos de que se utilizou para tentar convencer os alunos da justeza daquele artifício de ensino: o paciente estaria ciente de estar se tratando numa instituição de ensino, onde os estudantes ali se encontram para aprender. A apresentação poderia ser útil também para a paciente à medida que falaria para mais gente sobre o seu sofrimento. Para alunos, esta seria uma forma de aprender - escutar ao vivo o que os pacientes falam. Por último, apela ainda para a possibilidade dos alunos estabelecerem um vínculo com os pacientes, o que poderia servir de instrumento de ensino e tratamento.

Para esse autor, cada orientação teórica teria um posicionamento em relação a esta prática. Na fenomenológica, pela crença no "posicionamento intencional da consciência para um fenômeno mórbido, espera-se que possa emergir algo de sua essência, um fenômeno que se mostraria com poucas modificações em qualquer situação, desde que o método fosse aplicado corretamente" (p. 118). Já na orientação positivista, haveria a crença na presença de regularidades orgânicas, independentes do contexto. Aqui, a essência e a natureza dos eventos não seriam passíveis de trato pela ciência. O que deveria, então, ser ensinado nestas visões, seriam os traços comuns que os pacientes apresentam, já que os aspectos singulares não caberiam no método científico (Ibid.).

A terceira orientação é a psicanálise, que contrapõe a este tipo de prática, já que a noção de transferência tornaria o ensino incompatível com este modelo. Mas, como já assinalamos, seguindo a tradição lacaniana, alguns psicanalistas 


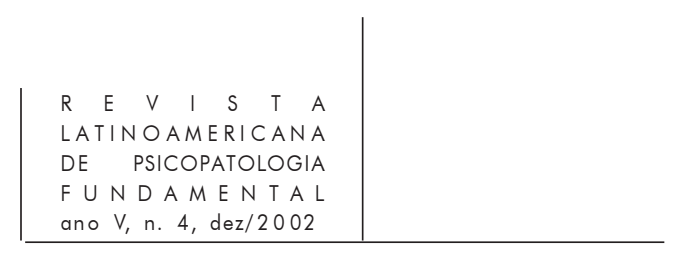

sustentam esta prática de ensino. Segundo Quinet (2001, p. 9), haveria aí uma convergência entre psicanálise e psiquiatria, pois ao acolher a fala do sujeito com o auxílio dos conceitos psicanalíticos, contribuiria para orientar o diagnóstico e o tratamento. Este autor parte do modelo de apresentação de Charcot, onde o paciente era tratado como objeto de observação e de exposição, para contrapô-lo ao método lacaniano, onde a prática de apresentação de pacientes teria se transformado em "encontro com um analista, com funções de ensino, diagnóstico, prognóstico e de orientação terapêutica a partir de uma clínica do sujeito inconsciente" (p. 86). Afirma ainda que, na apresentação de Lacan, não se tratava de mostração e ilustração de quadros clínicos, mas de entrevista, encontro, onde o analista seria ensinado.

Caon (2002) também afirma, a partir de sua prática de vários anos, que a apresentação psicanalítica de pacientes proporciona verdadeiras aulas de psicopatologia, à medida que o paciente seja reconhecido do lugar de sua constituição de sujeito desejante. Penso que a apresentação de pacientes não é a forma mais interessante do analista entrar na instituição psiquiátrica. Temo que essa prática possa retomar o clinicismo. O próprio Quinet (2001) assinala a falta das apresentações clássicas de Leme Lopes, exemplo este do clinicismo e do apego ao hospício.

Para Vertzman (1996), este tipo de ensino levaria às seguintes consequiências: primeiro, implicaria dizer aos alunos que podemos fazer os pacientes falarem de seu sofrimento, sem que isto se reverta terapeuticamente a seu favor e que esta conversa, não traria conseqüências para a sua evolução. $\mathrm{O}$ enunciado que sustenta esta prática seria: “... pode-se travar contato com o que chamamos de doença mental a partir de uma posição de puros observadores" (p. 119). Este ponto seria crítico, pois é impossível não se colocar numa posição moral diante do sofrimento psíquico do outro. Seria, portanto, um equívoco teórico, já que esta posição não consideraria a influência do contexto para a produção dos conteúdos, o que favoreceria, e até reforçaria, os estereótipos sobre o doente mental. Vemos, pois, que o rompimento com a prática clássica de ver pacientes implica novas proposições para o ensino. Podemos afirmar com Vertzman, que um bom ensino se faz num bom serviço.

Historicamente os asilos serviram para sistematizar a formação médica, que era precária até o século XVIII. Com a sua sistematização, houve um grande avanço em relação ao conhecimento das doenças e da terapêutica. Mas com a reclusão do doente e com a interiorização da doença no corpo do indivíduo, houve uma redução da compreensão da dimensão do sofrimento, e também dos seus fatores etiológicos. O modelo clinicista sofreu os efeitos da clausura ao centrarse na doença. Com isso, perdeu-se muito da dimensão da vida e dos fatores que sustentam a saúde. Pode-se observar a resistência em relação aos projetos de 


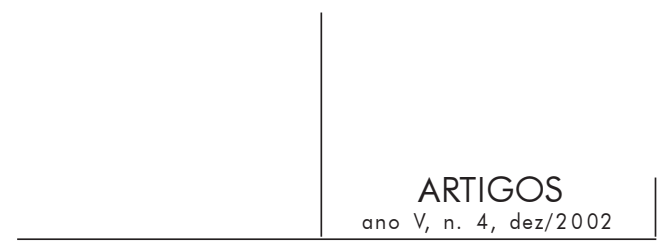

saúde pública, como foi no Brasil em relação aos projetos sanitaristas, onde Oswaldo Cruz teve que organizar um verdadeiro exército para higienizar o Rio de Janeiro. Hoje, quando várias práticas demonstram outras possibilidades de abordar o sujeito em sofrimento mental, cabe ao ensino da psicopatologia, encontrar outros métodos para abordar o sujeito em interação e não mais o indivíduo isolado.

Portanto, a transformação da prática de ensino envolve uma mudança na postura ideológica e ética que a sustenta, onde é exigido que o outro seja pensado em sua subjetividade e alteridade (Ferreira, 2000). O que engloba os vários profissionais que atuam na instituição, aos quais são reservados papéis geralmente subalternos e compartimentados. Trata-se, então, da possibilidade de se convocar a todos para assumirem seus lugares no elo terapêutico, onde o aluno de graduação deve também ser incluído. Ao contrário da posição clássica, deverá ser dito ao aluno que "tudo o que ele fizer ou disser, mesmo só observando, terá conseqüência para alguns sujeitos particulares ou para o serviço" (Vertzman, 1996, p. 120).

Diferentemente do leito hospitalar, a loucura vazava e extravasava no hospício, inundando os espaços e os sentidos. Para os alienistas, era um desafio conter esta polissemia na recém-inaugurada racionalidade médica. A apresentação de pacientes recortava na massa indiferenciada do hospício, um espaço de separação, para que o professor pudesse apresentar para os alunos as manifestações típicas das doenças no indivíduo. Respondia, na verdade, a uma demanda da formação clínica do psiquiatra que, em grande número, acorriam aos famosos hospícios europeus.

Se a alteridade do migrante, do louco, do índio, do negro ou do outro, é somada no negativo, torna-se difícil imaginar que seja possível alguma troca, é como se o outro não fosse também um eu, como foi com a representação do índio sem alma. Nesta perspectiva etnocêntrica, pode-se fazer qualquer coisa com este outro, já que ele não é circunscrito pela ética do dominante. A Europa foi violenta, tanto com os loucos quanto com os milhões de índios que foram dizimados no continente americano (Todorov, 1991; Ferreira, 1999). Recusado em sua diferença, o louco foi destituído da razão e a loucura de sentido. Sendo, portanto, excluído da interlocução, e sua fala singular deixou de ser escutada como mensagem do eu e do outro. Tornou-se mero objeto de captação de sinais-sintomas, comprovantes da sua não existência compartilhada. Assim, para incorporar o doente mental ao núcleo identitário ("nós, todos aqueles que pertencem ao mundo dos falantes”) (Vertzman, 1996, p. 121) há que se redimensionar os valores de inclusão e exclusão. Se a modernidade criou as cidades abertas, por outro lado estabeleceu rigidamente a delimitação dos pertencentes 


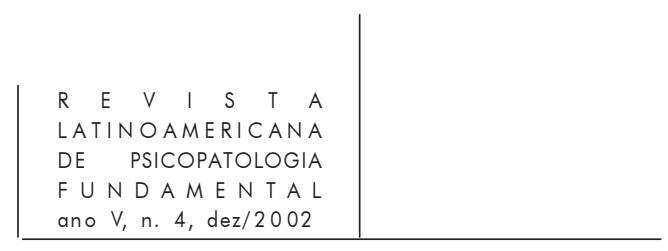

e dos excluídos. Para os designados como doentes mentais, essa divisão foi terrível.

$\mathrm{Na}$ ótica organicista, o paciente é tratado como um corpo físico ou anatômico, porque não se crê ser possível estar em jogo um corpo discursivo no apelo que este faz ao outro. Naquilo que se escuta da chamada loucura ou do delírio, muitas vezes o que se solicita é o reconhecimento de uma diferença (cf. Mannoni, 1976). O redimensionamento da comunicação com o psicótico exige a mudança do estatuto da loucura como alteridade radical e como sem sentido. O que não faz sentido é a exclusão de um pólo na comunicação, pois só é possível a comunicação onde o eu e o outro vivem sob o universo simbólico humano e, por tudo que sabemos, o psicótico continua bastante humano.

\section{Psiquiatria e psicanálise: interseções e suplementações}

A psicanálise nasce no campo da medicina e a partir do intrincamento do campo neuropsiquiátrico não diferenciado do final do século XIX. Freud teve sua curta experiência psiquiátrica orientada pelo clássico Meynert, no Hospital Geral de Viena (Pereira, 1998), além de sua estadia com Charcot e num hospital infantil. Ao iniciar sua clínica privada, herdara uma nomenclatura ainda pouco diferenciada das doenças mentais pré-kraepelinianas. Era leitor de Griesinger, clínico que descreveu magnificamente a melancolia (Almeida, 1999) e mais tarde se inteira da nosografia de Kraepelin. Inicia sua interlocução com Bleuler-Jung, com quem troca impressões constantes sobre as psicoses e sobre casos difíceis de diferenciação diagnóstica (Freud/Jung, 1986). Freud prestou importante contribuição, ao criar um corpo de conceitos precisos para reconhecer a histeria e a conversão histérica, além de possibilitar a diferenciação clara da neurose obsessiva e da angústia, que se achavam imbricadas em síndromes pouco diferenciadas. Também a concepção de esquizofrenia de Bleuler sofrerá os efeitos da experimentação da psicanálise na clínica psiquiátrica (Pereira, 1998), principalmente a partir dos experimentos e interlocuções dentre Jung e Freud (Freud/ Jung, 1986).

Durante muito tempo esta interlocução da psicanálise com a psiquiatria, iniciada pelos mestres, continuará. Foi somente após o quarto tempo da psiquiatria (Lantéri-Laura, apud Americano do Brasil, 2001, p. 2), que os moldes clássicos da clínica sofreram maiores reveses. Com o advento da psicofarmacologia no início da década 1950; a hegemonia da DSM-III, a partir da década de 1980, e com o fenômeno da globalização neoliberal, a psiquiatria foi sendo dominada 


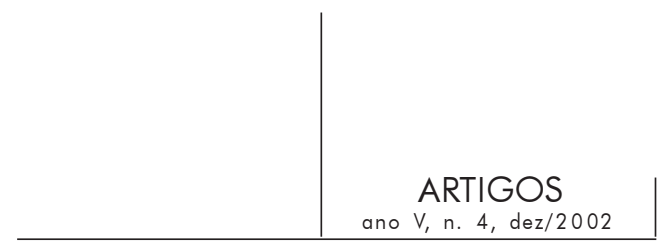

pela orientação operacional. ${ }^{5}$ Como afirma Roudinesco, citada por Quinet (2001, p. 8), a psicanálise serviu de cimento para a elaboração da nosologia psiquiátrica durante trinta anos, mas foi rejeitada em prol dos psicotrópicos e dos modelos das novas mitologias cerebrais e do DSM-IV. Ao afirmar-se ateórico, este sistema busca uma purificação ideológica para livrar-se do legado freudiano (Pereira, 1998, p. 70). Como afirma Lantéri-Laura (1989), este a-teórico é, na verdade, uma doxa, onde o empirismo é tomado como nova teoria.

Freud sempre enfatizou a importância da psicanálise para ajudar a psiquiatria a aprofundar a compreensão do psíquico e a superação de seu caráter meramente descritivo. Assinala (Freud, 1916, p. 302) que mesmo sendo impotente terapeuticamente, os benefícios da pesquisa poderiam advir, onde "cada pequena parcela de conhecimento se transformaria em poder terapêutico"; afirma ainda que "não há nada na natureza da prática psiquiátrica que possa se opor à psicanálise, a não ser os psiquiatras” (p. 301). É na prática clínica onde esta interlocução é exigida. Figueiredo (1999) propõe que a relação da psicanálise com a psiquiatria seja uma relação de suplementaridade - acrescentar algo, ir além. $\mathrm{O}$ trabalho do psicanalista viria suplementar o trabalho do psiquiatra, uma vez que "valoriza a palavra do paciente mesmo que esta não apresente a coerência exigida para uma conversa (...), no sentido de ajudar ao sujeito se situar em sua ação, seu delírio, ou seu sintoma. Há um valor de verdade na fala que deve ser reconhecido" (p. 88).

Quinet (2001) procura ressaltar os pontos de convergência entre a psicanálise e a psiquiatria. Seguindo Freud, ele afirma a necessidade da continuidade destas práticas, pois ao seguir meramente os manuais de diagnóstico e prescrever a substância estabelecida pelas neurociências, o psiquiatra estaria "pondo em risco a existência da clínica psiquiátrica” (p. 9). Com Lacan, Quinet (p. 10) enfatiza a participação da psicanálise na formação do psiquiatra, para que em sua clínica ele deixe surgir os fatos subjetivos. Se houver na prática psiquiátrica uma atenção para as manifestações do inconsciente, do desejo, da tristeza, da angústia e dos sintomas em geral como manifestações subjetivas, haveria aí uma chance de convergência entre as duas.

5. O sistema operacional pretende que os termos derivem da própria ação. Segundo Ionescu (1997, p. 22), são critérios descritivos, com definições precisas e de fidelidade interjuizes. Pereira (1997, p. 109) exemplifica esta forma de proceder com o exemplo paradigmático da síndrome do pânico, cujo diagnóstico é definido a partir da eficácia da imipramina. Esta categoria "reunia, sob critérios empíricos, operacionalmente organizados, aqueles pacientes cujos sintomas eram suscetíveis de melhora com tratamento à base de imipramina". 


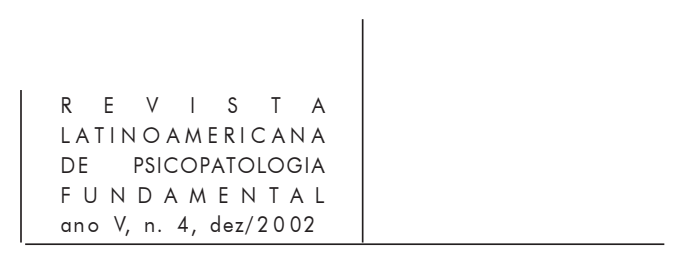

Para Pereira (1998), a psicanálise vai confrontar as principais correntes psicopatológicas, ao instaurar a dimensão da subjetividade no centro da psicopatologia. Primeiro o empirismo, já que a psicanálise rejeita a idéia de isenção do observador, ao afirmar que "não há fato a observar, pois o que está em questão não são os eventuais sintomas do sofrimento anímico, mas um discurso pronunciado em torno de uma queixa de falta de gozo" (p. 72). Quanto à fenomenologia "vai contestar a possibilidade de qualquer compreensão da dor do outro, pois, naquilo que tem de essencial, ela é totalmente irredutível às minhas próprias imagens do sofrer (...)" (p. 72).

A partir de todas estas considerações, depreendemos que a psicanálise é a interlocutora privilegiada da psicopatologia fundamental.

\section{Psicopatologia Fundamental: a pesquisa inclinada para o sujeito do páthos}

A criação de Laboratório de Psicopatologia Fundamental surgiu na Universidade Paris VII, com Pierre Fédida, há mais de trinta anos e inspirou a experiência brasileira liderada pelo professor Manoel Berlinck. Em 1995, Berlinck criou o primeiro Laboratório no Programa de Estudos Pós-Graduados em Psicologia Clínica da PUC de São Paulo. Em 1997, ele teve a generosa iniciativa de lançar uma chamada aos professores universitários interessados pela área e, fundou, assim, a Rede Universitária de Pesquisa em Psicopatologia Fundamental (Berlinck, 2000). ${ }^{6}$ Consideramos este projeto bastante promissor e seus frutos podem ser avaliados pelos encontros científicos, congressos e publicações já realizados.

O primeiro ponto que assinalamos é o ganho de autonomia do campo de ensino da psicopatologia, no sentido de liberar-se do espaço de reclusão. Como assinalamos acima, este ensino tem a longa tradição dos hospícios. O segundo ponto a destacar relaciona-se com a criação de laboratórios de pesquisa nos espaços universitários. O compromisso com a pesquisa poderá trazer importantes contribuições, posto que, nas últimas décadas, houve um estacionamento da pesquisa psicopatológica. Já se pode ter acesso a uma produção relevante neste sentido, seja através da Revista Latinoamericana de Psicopatologia Fundamental, que já está no terceiro ano, seja pelos livros que vêm sendo lançados.

Para conceituar a psicopatologia fundamental, Berlinck (2000) faz um retorno à Grécia antiga, visando resgatar a potência do conceito de páthos. De páthos deriva sofrimento, paixão e passividade, desta forma, a psicopatologia 


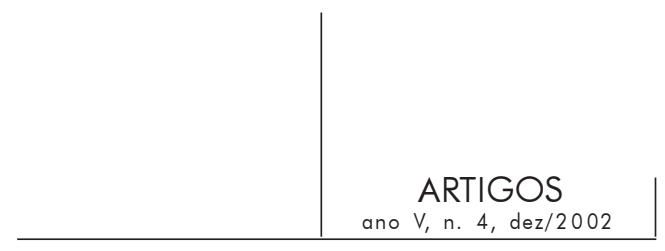

fundamental "está interessada num sujeito trágico que é constituído e coincide com o páthos, o sofrimento, a paixão, a passividade” (p. 18). A condição de paciente surge justamente por este submetimento. Há um sujeito tocado por algo que desloca o lugar de domínio, colocando o sujeito em movimento, de uma indeterminação a uma nova posição que depende da intervenção de um agente. "O páthos é sempre provocado pela presença ou imagem de algo que me leva a reagir. Ele é o sinal de que eu vivo na dependência permanente do Outro" (p. 20).

A referência para definir a psicopatologia seria o sofrimento ou a paixão, no sentido de uma passividade que "porta em si mesmo a possibilidade de um ensinamento interno que não ocorre a não ser pela presença de um médico ou terapeuta" (p. 21). Berlinck afirma a positividade do páthos por envolver um estado que produz demanda. Ele destaca a importância do estudo dos efeitos do discurso sobre os homens, para que seja possível "fazer com que o páthos perca o seu sentido mais amplo de fenômeno passivo para vir a designar as percepções da alma (p. 22).

Depreendemos daí, acompanhando este autor, que psicopatologia fundamental é uma posição em que o terapeuta se inclina diante de alguém que porta uma voz única a respeito de seu páthos, sempre objeto da transferência: “de um discurso que narra o sofrimento, as paixões, a passividade que vem de longe e de fora e que possui um corpo onde brota um interlocutor que, por suposição, seja capaz de transformar, com o sujeito, essa narrativa numa experiência” (p. 23).

Neste sentido, diferenciar-se-ia da psicopatologia geral, pois nesta, teríamos um discurso a respeito das doenças, das formas corporais-discursivas que assumem o páthos, enquanto a psicopatologia fundamental estaria interessada em suscitar uma experiência que seja compartilhada pelo sujeito (Ibid.). A potencialidade do sofrimento e do submetimento do páthos e da paixão perde seu valor ao ser reduzida ao significado de enfermidade e de defeito (Caon, 2002).

Retomando Berlinck e Fédida, Pereira (1998, p. 74) enfatiza a relação da psicopatologia com a paixão ou páthos grego, onde o sofrimento comporta a possibilidade de transformar-se em sabedoria na medida em que possa "ser escutado por um outro que sustente a palavra do sofredor até que ela atinja seus extremos de auto-engendramento de um sujeito". Portanto, a psicopatologia fundamental visa trabalhar uma clínica que "resgate da paixão e do sofrimento sua capacidade geradora de sabedoria” (p. 75).

Entendemos que o caminho apontado pela psicopatologia fundamental, ao propor este campo de pesquisa, que se inclina sobre o sujeito do páthos e procura resgatar a dimensão de implicação subjetiva na constituição do sofrimento, contrapõe-se ao domínio hegemônico dos DSM, que reduzem o psicopatológico aos quadros sindrômicos descritos em forma de tabelas. Do ponto de vista do ensino, acreditamos que, por meio dos núcleos de pesquisa (Laboratórios), seja 


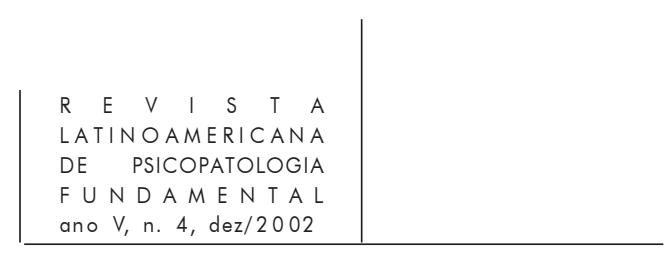

possível criar novas condições de transmissão, sustentadas em metodologias com bases epistemológicas bem fundamentadas. O ensino clínico deve ser feito a partir da experiência clínica, onde os serviços de psiquiatria - não somente a clínica da internação, mas também a clínica aberta, sem hospício e sem reclusão podem funcionar como importantes campos de prática e transformação da prática, através do compromisso dos alunos com a terapêutica. Ao mesmo tempo, é fundamental refletir sobre a história da psiquiatria e das representações sociais que reforçam a exclusão do louco e da loucura. Recolocar em circulação esta alteridade excluída, é resgatar uma importante dimensão obliterada de nossas práticas sociais, o que, certamente, empobreceu nossa humanidade.

\section{Considerações finais}

Não é fácil estabelecer códigos lingüísticos que possam transmitir conceitos intercomunicáveis em psicopatologia. A comunidade científica encontra muitas dificuldades para estabelecer parâmetros comuns. Para se fazer diagnóstico em medicina, foi necessário que as doenças estivessem definidas. Esta condição parece ter sido preenchida pela psiquiatria, por meio das descrições minuciosas dos quadros nosográficos dos clássicos e que foram sistematizados por kraepelinianos no final do século XIX. Mas este é o primeiro dos três estágios que acompanham a epistemologia médica (Kammerer/Wartel, 1989). O segundo estágio, de localização do substrato anatômico, se foi reconhecido em alguns quadros - síndromes focais - muitas destas deixaram de ser matéria psiquiátrica e passaram para o campo da neurologia. Quanto ao terceiro, precisar o agente etiológico, sempre foi problemático. Com a PGP, a medicina cumpriu suas etapas, mas o tratamento etiológico não é psiquiátrico e a demência paralítica não é modelo para a esquizofrenia.

Diante das dificuldades com o modelo da etiologia, o pragmatismo americano assumiu a dianteira neste sentido, ao formular amplo intercâmbio entre os psiquiatras para criar parâmetros universais e consensuais. A definição empírico-pragmática das entidades psicopatológicas, que resultou no Manual de Diagnóstico e Estatística da Associação Psiquiátrica Americana, atual DSM-IV, tornou-se hegemônica (Pereira, 1998; 2000). Para atingir sua meta de estabelecer um acordo sobre as categorias diagnósticas, esta corrente abriu mão da idéia de entidade mórbida e do critério etiológico. Os diagnósticos passam a ser meras convenções de caráter pragmático. "Não se trata mais de tentar exprimir ou descrever a essência do sofrimento humano, nem mesmo especular sobre suas possíveis determinações" (Pereira, 1998, p. 62). 


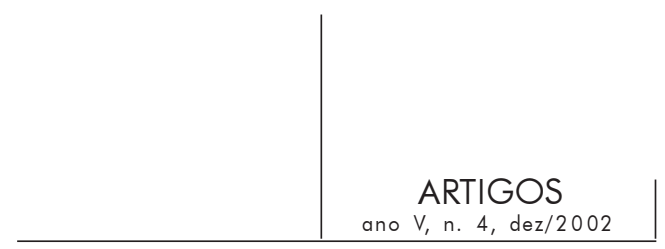

A psiquiatria sempre buscou a autoridade da medicina para sua sustentação sociojurídica, a tolerância da aproximação com a psicanálise ocorreu pela autoridade que esta ganhou no século XX. Houve também a necessidade de incorporar suas contribuições, tanto as teóricas quanto as terapêuticas, sobre as neuroses, pois a psiquiatria do final do século não as reconhecia e não tinha o que fazer com elas. A partir dos psicotrópicos, as neuroses também vão entrando no campo dos tratamentos sintomáticos e os médicos começam a querer explicá-las pelo modelo fisicista. Mas se o psiquiatra seguir meramente este modelo e os manuais de diagnóstico, prescrevendo simplesmente as drogas estabelecidas pelas neurociências, ele estaria colocando em risco a própria existência da clínica psiquiátrica (Quinet, 2001, p. 9), até mesmo porque qualquer médico receita psicotrópico. Sem uma reflexão mais aprofundada, os psicotrópicos continuarão como meros tapadores do mal-estar. Como afirmou o criador dos psicotrópicos, Laborit, citado por Americano do Brasil (p. 56), “A humanidade, ao longo de sua evolução, foi obrigada a passar pelas drogas. Sem os psicotrópicos, talvez tivesse havido uma revolução na consciência humana..."

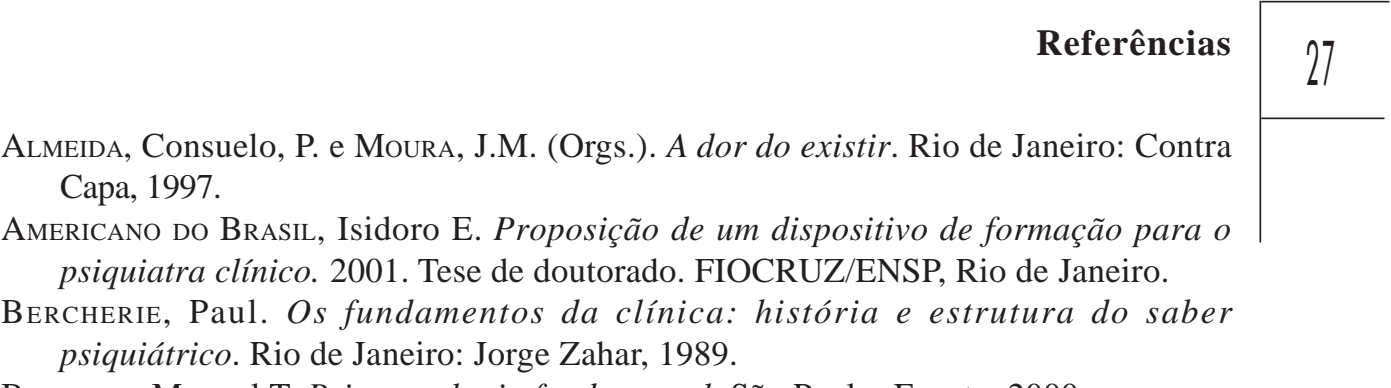

Berlinck, Manoel T. Psicopatologia fundamental. São Paulo: Escuta, 2000.

CAOn, José L. A psicopatologia fundamental e a miséria da psicopatologia: formadores e deformadores do psicopatólogo. In: Queiroz, E.F. e Silva, A.R. Rodrigues da (Orgs.). Pesquisa em psicopatologia fundamental. São Paulo: Escuta, 2002.

Cheniaux JR., Elie. Manual de psicopatologia. Rio de Janeiro: G -Koogan, 2002.

Clérambault, Gaëtan G. O automatismo mental e a erotomania. Revista Latino Americana de Psicopatologia Fundamental. São Paulo, v. IV, n. 2, p. 125-33, 2001.

Ferreira, A. Pacelli. Ação e reflexão no campo dos cuidados. In: Alberti, S. e Elia, L. Clínica e pesquisa em psicanálise. Rio de Janeiro: Rios Ambiciosos, 2000.

$O$ migrante na rede do outro: ensaios sobre alteridade e subjetividade. Rio de Janeiro: Te Corá, 1999.

A residência hospitalar como modalidade de especialização em psicologia clínica. Psicologia, Ciência e Profissão, Conselho Federal de Psicologia, ano 21, n. 2, 2001. 


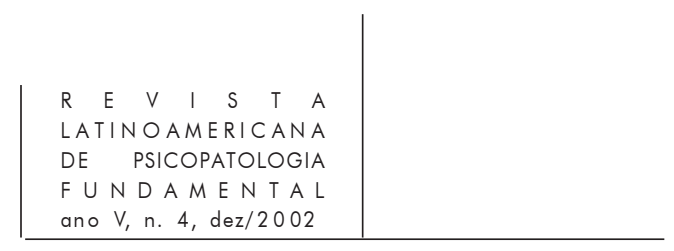

Figueiredo, Ana C. A relação entre psiquiatria e psicanálise: uma relação suplementar. Rio de Janeiro, Inform. Psiq. v. 18, n. 3, p. 87-9, 1999.

Figueiredo, A.C. e Silva Filho, J.F. (Org). Ética e saúde mental. Rio de Janeiro: Topbooks, 1996.

Foucault, M. O nascimento da clínica. Rio de Janeiro: Forense-Universitária, 1977.

Freud/Jung. Correspondência. Rio de Janeiro: Imago, 1976.

Freud, S. [1907]. Delírios e sonhos na Gradiva de Jensen. E.S.B. Rio de Janeiro: Imago, 1976. v. IX.

[1911]. O caso Schreber. E.S.B. Rio de Janeiro: Imago, 1969. v. XII.

[1916]. Psicanálise e psiquiatria. Conferências introdutórias sobre psicanálise. E.S.B. Rio de Janeiro: Imago, 1976. v. XVI.

IonESCu, Serban. Quatorze abordagens de psicopatologia. 2a ed. Porto Alegre: Artes Médicas, 1997.

Kammerer, T. e Wartel, R. Diálogo sobre os diagnósticos. In: Strauss, M. e outros, A querela dos diagnósticos. Rio de Janeiro: Jorge Zahar, 1989.

LANTÉRI-LAURA, Georges. O empirismo e a semiologia psiquiátrica. In: A querela do diagnóstico. Op. cit.

Mannoni, Maud. O psiquiatra, seu louco e a psicanálise. Rio de Janeiro: Jorge Zahar, 1976.

Pereira, Mário E.C. Formulando uma psicopatologia fundamental. Revista Latinoamericana de Psicopatologia Fundamental. São Paulo, v. I, n. 1, mar/1998. O automatismo mental e a erotomania, segundo Clérambault. Revista Latinoamericana de Psicopatologia Fundamental. São Paulo, v. II, n. 1, mar/1999. Pânico: contribuições à psicopatologia dos ataques de pânico. São Paulo: Lemos, 1997.

Pânico e desamparo. São Paulo: Escuta, 2000.

Quinet, Antonio (Org.). Psicanálise e psiquiatria. Rio de Janeiro: Rio Ambiciosos, 2001.

SilveirA, Nise. Imagens do inconsciente. Rio de Janeiro: Alhambra, 1982.

Todorov, Tzvetlan. A conquista da América: a questão do outro. 3a ed. São Paulo: Martins Fontes, 1991.

Vertzman, J. S. Será possível transformar a prática do ensino prático?. In: FigueiRedo, A.C. e Silva Filho, J. F. Ética e saúde mental. Rio de Janeiro: Topbooks, 1996.

\section{Resumos}

La cuestión de la enseñanza de la psicopatología es aquí abordada a partir de retomar los elementos de la historia de la constitución de la clínica médica y de los clásicos, hasta la constitución de la psiquiatría clínica. En ese recorrido, se analizan 


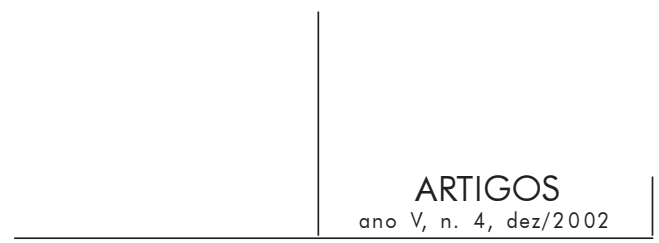

los instrumentos nacidos de la atención cuidadosa de los padecimientos y, posteriormente, con la conquista del dominio sobre la enfermedad a través de la nosografía, donde la marca pesimista del asilo tornó la clínica un ejercicio escolástico. Se propone, en consecuencia, un retorno a la clínica contra el empiricismo y el esencialismo clinicista.

Palabras claves: Clínica clásica, psicopatología, enseñanza

La question de l'enseignement de la psychopatologie est abordée ici, à partir de la reprise des élements de l'histoire de la constitution de la médecine clinique et des auteurs classiques, jusqu'à la constitution de la psychiatrie clinique. On y analyse les instruments nés d'abord, d'une attention particuliére portée à la souffrance et, postérieurement, de la conquête de la maitrise de la maladie grâce à la nosographie - à partir de ce moment, la connotation pessimiste de l'asile a transformé la clinique en un exercice scolastique. On propose alors de revenir à la clinique, abandonnant l'empirisme et l'essencialisme clinique.

Mots clés: Clinicisme, nosographie, enseignement, psychopatologie fondamentale

The question of the teaching of psychology is taken up here based on factors related to the constitution of medical clinic, of the classics, and of the constitution of the psychiatric clinic. Also analyzed are instruments born of careful attention to suffering and, later, to the domination over illness through nosography, where the pessimistic mark of the asylums turned the clinic into academic exercise. A return to the clinic against empiricism and clinicist essentialism is therefore proposed.

Key words: Clinicism, nosography, teaching, fundamental psychophatology

Versão inicial recebida em fevereiro de 2002

Aprovado para publicação em novembro de 2002 